\title{
Caracterização botânica e avaliação do potencial antimicrobiano do mel produzido por Apis mellifera L., Melipona scutellaris Latreille e Tetragonisca angustula Latreille (Hymenoptera: Apidae) em um fragmento de floresta ombrófila densa no estado da Bahia, Brasil
}

Botanical characterization and evaluation of the antimicrobial potential of honey produced by Apis mellifera L., Melipona scutellaris Latreille and Tetragonisca angustula Latreille (Hymenoptera: Apidae) in a fragment of dense rainforest in the State of Bahia, Brazil

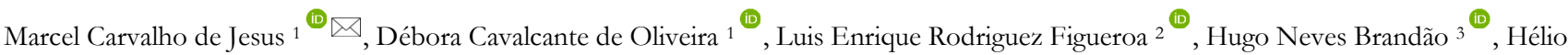
Mitoshi Kamida ${ }^{(1)}$ \& Francisco de Assis Ribeiro dos Santos ${ }^{(1)}$

1. Programa de Pós-graduação em Botânica, Universidade Estadual de Feira de Santana, Feira de Santana, Bahia, Brasil.

2. Departamento de Ciências Exatas e da Terra - Campus II/Alagoinhas, Universidade do Estado da Bahia, Alagoinhas, Bahia, Brasil.

3. Programa de Pós-graduação em Recursos Genéticos Vegetais, Universidade Estadual de Feira de Santana, Feira de Santana, Bahia, Brasil.

4. Programa de Pós-graduação em Biotecnologia, Universidade Estadual de Feira de Santana, Feira de Santana Bahia, Brasil.

Palavras-chave

Melissopalinologia. Pólen. MIC.

Keywords

Melissopalynology. Pollen. MIC.

Doi

doi.org/10.33447/paubrasilia.v3i2.40

Recebido em: 27/05/2020

Aceite em: 05/08/2020

Editor responsável: Gleidson V. Marques (UFSB)

ISSN: 2595-6752

Tardim OButauice FLORAS

\section{Resumo}

Este estudo busca caracterizar, através dos grãos de pólen, a origem botânica de amostras de mel produzido por Apis mellifera, Melipona scutellaris e Tetragonisca angustula, identificando recursos vegetais partilhados e analisando também a capacidade antimicrobiana das amostras. Trinta amostras foram analisadas e 13 apresentaram atividade antimicrobiana contra Staphylococcus aureus. Foram identificados 154 tipos polínicos compondo o espectro polínico dos méis analisados; 133 tiveram sua afinidade botânica inferida. Desses tipos polínicos, 82 foram observados nos méis de $M$. scutellaris, 75 nos méis de $A$. mellifera e 56 nos de T. angustula. Vinte tipos polínicos foram compartilhados nos méis das três espécies de abelha, merecendo destaque, por sua representatividade, as famílias Myrtaceae e Fabaceae. Apenas sete tipos ocuparam a classe de frequência de pólen dominante. A partir dos dados levantados, observa-se que os méis estudados se caracterizam como multiflorais e apenas alguns deles apresentam atividade antimicrobiana contra $S$. aureus.

\section{Abstract}

This study aimed to characterize, through pollen grains, the botanical origin of honey samples produced by Apis mellifera, Melipona scutellaris, and Tetragonisca angustula, identifying shared plant resources and also analyzing the antimicrobial capacity of the samples. Thirty samples were analyzed and 13 showed antimicrobial activity against Staphylococcus aureus. One hundred fifty-four pollen types were identified composing the pollen spectrum of the analyzed honey; 133 had their botanical affinity inferred. Of these pollen types, 82 were observed in the boney of $\underline{M}$. scutellaris, 75 in $\underline{A}$. mellifera and 56 in $\underline{T}$. angustula. Twenty pollen types were shared in the honey of all bee species; the Myrtaceae and Fabaceae families standing out for their representativeness. Only seven types were classified as predominant pollen. The honey samples are characterized as multifloral, and only some of them have antimicrobial activity against $\underline{S}$. aureus. 


\section{Introdução}

A longa coevolução de abelhas e angiospermas resultou em uma relação abelha-planta intrincada e mutuamente benéfica. Para as abelhas, o néctar das plantas e o pólen são as principais fontes alimentares de carboidratos e proteínas. Por outro lado, as plantas precisam de polinizadores (Erler; Moritz, 2016; Bankova et al., 2018). Para que essa coevolução mantenha sucesso é imprescindível que as plantas forneçam alimentos livres de patógenos para as abelhas. Assim, o néctar oferecido por uma flor não deve ser fermentado, nem o pólen deve estar contaminado com patógenos fúngicos. Portanto, não é surpreendente que as plantas adicionem metabólitos especializados ao néctar para impedir a degradação microbiana (Stevenson et al., 2017; Bankova et al., 2018).

Dessa forma, enquanto forrageiam para satisfazer sua demanda nutricional básica, as abelhas inevitavelmente coletam metabólitos especializados das plantas como parte do néctar e do pólen. Em geral, estes compostos possuem atividade biológica que pode ser relevante para combater pragas e patógenos não só na colmeia (Bankova et al., 2018).

Utilizado há séculos como alimento natural e como medicamento, o mel é resultado da desidratação e transformação do néctar, a partir da combinação com substâncias próprias das abelhas. Geralmente, o mel é composto por uma complexa mistura de carboidratos, apresentando outras substâncias menos frequentes, como ácidos orgânicos, aminoácidos, proteínas, vitaminas, lipídios, compostos aromáticos, flavonoides, grãos de pólen e outras substâncias (Almeida-Muradian et al., 2013).

Os efeitos bactericida e bacteriostático do mel sobre diversos microrganismos Gram-positivos e Gram-negativos já são bem documentados na literatura, assim como seus efeitos antifúngicos. A possiblidade de eliminar esses microrganismos é atribuída à osmolaridade, ao $\mathrm{pH}$, à concentração de $\mathrm{H}_{2} \mathrm{O}_{2}$ (peróxido de hidrogênio) e à presença de outros compostos fitoquímicos naturais, i.e. seu conteúdo de derivados da tetraciclina, peroxidases, amilases, ácidos graxos, fenóis, ácido ascórbico, flavonoides, estreptomicina, sulfatiazol, terpenos, álcool benzílico e ácidos benzóicos (Molan, 1992; Mulu et al., 2004; Montenegro; Mejías, 2013).

Um dos principais problemas para aplicação do mel em diferentes usos - e.g. como parte de cosméticos, aditivos alimentares, dispositivos médicos ou medicamento - é a necessidade de padronização do produto. Sem dúvidas, o problema mais significativo atrelado a isto é a variabilidade de sua composição química, determinada em maior grau pelas diversas plantas utilizadas e pelas espécies de abelhas transformadoras.

Nesse contexto, a melissopalinologia apresenta-se como uma importante ferramenta, pois atua na obtenção de dados sobre o comportamento de forrageamento das abelhas, à medida que desempenha papel eficaz na avaliação da origem botânica e até geográfica do mel, assegurando sua qualidade (Jones; Bryant Jr., 2004). Assim, os dados gerados a partir das análises palinológicas do mel são extremamente valiosos no processo de padronização do produto.

O presente estudo tem como objetivo identificar o espectro polínico presente nos méis produzidos por uma mesma colmeia, de três espécies diferentes de abelhas - Apis mellifera Linnaeus, 1758,
Melipona scutellaris Latreille, 1811 e Tetragonisca angustula Latreille, 1811 - durante o período de um ano, avaliando também o potencial antimicrobiano das amostras.

\section{Material e Métodos}

Área de estudo

A pesquisa foi conduzida em um fragmento florestal ombrófilo denso localizado no município de Alagoinhas, Bahia, sob as coordenadas $12^{\circ} 10^{\prime} 42^{\prime \prime} \mathrm{S}$; $38^{\circ} 24^{\prime} 43^{\prime \prime} \mathrm{W}$, altitude de $150 \mathrm{~m}$, com área de 150 ha, pertencente à Universidade do Estado da Bahia (UNEB), campus II - Alagoinhas. Nessa área são mantidas as colônias de abelhas cujos méis foram extraídos para análises (Figura 1).

Figura 1. Localização da área de estudo, município de Alagoinhas, Bahia, Brasil. a. Mapa do Brasil com destaque no estado da Bahia. b. Mapa da Bahia com destaque no Município de Alagoinhas c. Município de Alagoinhas com indicação da área de estudo.

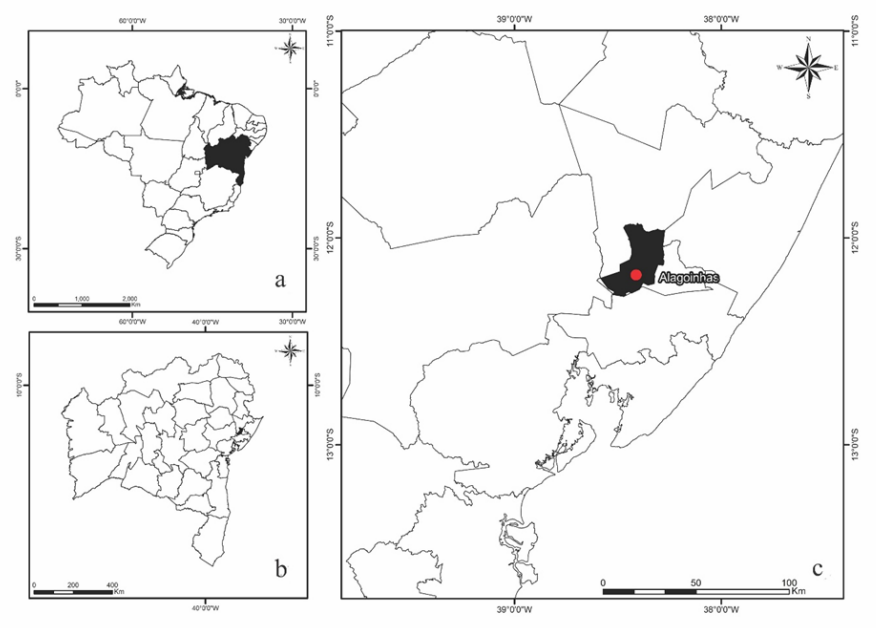

Amostragem

As amostras de mel utilizadas neste trabalho foram coletadas mensalmente durante o período de outubro de 2016 a setembro de 2017, totalizando 30 amostras analisadas. Nos meses de junho e julho de 2017, as colmeias não apresentaram produção de mel suficiente para retirada das amostras. A codificação das amostras foi realizada utilizando-se as letras iniciais da espécie de abelha, do produto estudado e do mês de coleta.

\section{Preparação das amostras de mel para análise microbiológica}

A umidade das amostras de mel foi mensurada por refratometria a $20^{\circ} \mathrm{C}$ e a interpretação dos resultados feita através da tabela de Chataway (Instituto Adolfo Lutz, 2008). Após este processo, alíquotas de mel foram pesadas e, considerando seus teores de umidade e sólidos dissolvidos, diluídas em água ultrapura - essa medida visou a equilibrar a maior umidade presente nos méis de abelhas-sem-ferrão. A mistura foi filtrada utilizando-se membrana com poros de $0,22 \mu \mathrm{m}$ de diâmetro. Os méis foram testados em concentrações que variaram de 10 a $0,1 \mathrm{mg} / \mathrm{mL}$. 
Análise da atividade antimicrobiana das amostras

As amostras de mel foram avaliadas quanto à atividade antimicrobiana aplicando-se testes de microdiluição em caldo, segundo os protocolos e adaptações propostos por Clinical and Laboratory Standards Institute - CLSI (2008; 2012). As amostras foram testadas em triplicata contra os microrganismos Escherichia coli (Migula) Castellani and Chalmers (ATCC ${ }^{\circledR} 25922^{\mathrm{TM}}$ ), Psendomonas aeruginosa (Schroeter) Migula (ATCC ${ }^{\circledR} 27853^{\mathrm{TM}}$ ), Staphylococcus aureus subsp. aureus Rosenbach (ATCC ${ }^{\circledR} 25923^{\mathrm{TM}}$ ) e a levedura Candida albicans (Robin) Berkhout (ATCC ${ }^{\circledR} 10231^{\mathrm{TM}}$ ). A concentração inibitória mínima (MIC), parâmetro adotado para avaliar a atividade antimicrobiana, foi realizada segundo as sugestões do CLSI expressas nos documentos M27-A3 (CLSI, 2008) e M07-A09 (CLSI, 2012).

$\mathrm{O}$ inóculo bacteriano foi ajustado a partir da escala $0.5 \mathrm{Ma}-$ cFarland $\left(1 \times 10^{8} \mathrm{UFC} / \mathrm{mL}\right)$ para obtenção da concentração final no poço de $5 \times 10^{5} \mathrm{UFC} / \mathrm{mL}$. Para $C$. albicans, o inóculo foi ajustado a uma concentração final de $0,5 \times 10^{3}$ a $\left.2,5 \times 10^{3} \mathrm{UFC} / \mathrm{mL}\right)$. As placas de microdiluição inoculadas com bactérias foram incubadas a $35^{\circ} \mathrm{C}$, durante um período de 24 horas em estufa bacteriológica, e as placas contendo leveduras, incubadas a $35{ }^{\circ} \mathrm{C}$, durante período de 48 horas, em incubadora B.O.D.

Para auxílio na leitura dos resultados, a substância cloreto de 2, 3, 5-trifeniltetrazólio na concentração de $0,5 \%$ - que atua como revelador do crescimento microbiano -, foi utilizada após o período de incubação, procedendo-se à leitura das placas uma hora depois de acrescentada a substância. Como controles negativos foram utilizados os antibióticos cloranfenicol $(30 \mu \mathrm{g} / \mathrm{mL})$ e gentamicina $(10 \mu \mathrm{g} / \mathrm{mL})$ para as bactérias e o antifúngico nistatina (100000 U.I./ ml) para a levedura.

\section{Processamento palinológico}

O processamento palinológico das amostras de mel seguiu o método proposto por Louveaux et al. (1978), com adoção da dissolução da mistura de mel e água em etanol a 95 \% (proporção 1:1:5), adaptação sugerida por Jones e Bryant Jr. (2004) que visa a minimizar a perda de grãos de pólen. Após este processo, o sedimento polínico resultante foi submetido à acetólise conforme Erdtman (1960). Cada amostra de mel teve seu conteúdo polínico preparado em cinco lâminas contendo gelatina glicerinada, uma delas contendo gelatina glicerinada com safranina. Essa última, utilizada apenas para a realização de fotomicrografias e observação de estruturas que se apresentem melhor evidentes quando coradas, fornecendo dados para a correta identificação do grão de pólen.

\section{Identificação e contagem polínicas}

A identificação dos tipos polínicos encontrados nas quatro lâminas preparadas com gelatina glicerinada não corada foi realizada a partir de comparação com as lâminas de referência depositadas na palinoteca do Laboratório de Micromorfologia Vegetal (LAMIV) na Universidade Estadual de Feira de Santana (UEFS) e através de comparação com atlas palinológicos (Moncada; Salas, 1983; Roubik; Moreno, 1991; Martínez-Hernandez et al., 1993;
Carreira; Barth, 2003; Melhem et al., 2003; Silva et al., 2016, Lorente et al., 2017). Os tipos polínicos relacionados às espécies do gênero Mimosa (Fabaceae) estão em concordância com Lima et al. (2008). Todos os tipos polínicos identificados foram organizados conforme o sistema de classificação das Angiospermas APG IV (2016). O conceito de tipo polínico adotado seguiu as recomendações dos autores Joosten e de Klerk (2002) e Santos (2011). Foram quantificados 500 grãos de pólen por amostra de mel, utilizando as quatro lâminas preparadas em gelatina glicerinada não corada. Em seguida, adotaram-se as classes de frequência para tipos polínicos estabelecidas por Louveaux et al. (1978).

Análise estatistica

Para realização da análise de componentes principais (PCA) foi utilizado o software livre PAST versão 4.02 (Hammer et al., 2001). Apenas dados palinológicos foram utilizados na análise.

\section{Resultados e Discussão}

Inúmeros méis de diferentes domínios fitogeográficos, origens florais e abelhas vem sendo testados ao longo do tempo contra uma grande diversidade de microrganismos. No entanto, é desconhecido um trabalho anterior a este que acompanhe uma colônia de três diferentes espécies de abelhas durante um ano de produção, avaliando o potencial antimicrobiano do mel produzido e seu espectro polínico. Incontáveis também são as diluições testadas que produzem resultados singulares para cada um dos méis, que em sua maioria não possuem uma origem botânica identificada. Esse é um ponto no qual os estudos melissopalinológicos tornam-se ferramentas indispensáveis, revelando dados importantes sobre a flora visitada pelas abelhas para composição do mel.

Cabe ressaltar, ainda, que os poucos estudos que buscam avaliar e comparar o potencial antimicrobiano de amostras pontuais de méis de diferentes espécies de abelhas, e identificar a concentração inibitória mínima (MIC) das amostras, desconsideram o fato das amostras de mel terem umidades diferentes, principalmente no que se refere a amostras de abelhas sem ferrão. Estas, em sua maioria, apresentam umidade superior às encontradas em amostras de $A$. melifera, produzindo, assim, diluições finais maiores do que as esperadas e não equivalentes para comparação.

A análise polínica das amostras em estudo revelou um total de 154 tipos polínicos compondo o espectro polínico dos méis. Segundo Jesus et al. (2017), a flora identificada da região ao redor das colmeias é composta por 277 espécies de plantas. Assim, mais da metade das plantas localizadas no entorno das colmeias são utilizadas para a fabricação dos méis. Do total de tipos polínicos, 133 tiveram sua afinidade botânica inferida (Figura 2), merecendo destaque, por sua representatividade nos méis, as famílias Myrtaceae e Fabaceae, também apontadas como detentoras dos maiores números de espécie na flora da região (Jesus et al., 2017).

Entre os tipos polínicos identificados, 75 foram observados nos méis de $A$. mellifera (Tabela 1, Figura 3), 82 nos méis de $M$. scutellaris (Tabela 2, Figura 3) e 56 nos de T. angustula (Tabela 3, 
Tabela 1. Concentração (\%) de tipos polínicos encontrados nos méis de Apis mellifera.

\begin{tabular}{|c|c|c|c|c|c|c|c|c|c|c|}
\hline Tipos polínicos & $\mathrm{AMO}$ & $\mathrm{AMN}$ & AMD & AMJ & AMF & AMM & AMA & AMMa & AMAg & $\overline{\mathrm{AMS}}$ \\
\hline \multicolumn{11}{|l|}{ Anacardiaceae } \\
\hline Schinus terebinthifolius & - & 4,4 & 13 & 13 & - & - & 2,4 & - & - & 0,4 \\
\hline Spondias tuberosa & - & - & - & - & 3 & - & 1,6 & 1,3 & - & - \\
\hline Tapirira guianensis & - & - & - & - & 36,6 & 14,4 & 23,4 & 51,2 & - & 0,9 \\
\hline \multicolumn{11}{|l|}{ Arecaceae } \\
\hline Bactris & - & - & - & 0,2 & - & 0,4 & - & - & - & - \\
\hline Cocos nucifera & - & - & - & - & - & - & - & 0,8 & - & 3,2 \\
\hline Syagrus & - & - & - & - & - & - & 0,2 & - & - & - \\
\hline \multicolumn{11}{|l|}{ Asteraceae } \\
\hline Asteraceae 1 & 0,2 & - & - & - & - & 0,6 & - & - & - & - \\
\hline Asteraceae 2 & 0,2 & - & - & - & - & 0,2 & - & - & - & - \\
\hline Baccharis retusa & - & - & 0,9 & - & - & - & - & - & - & - \\
\hline Chaptalia nutans & - & - & - & 0,8 & - & - & - & - & - & - \\
\hline Elephantopus & - & - & 0,2 & - & - & - & - & - & - & - \\
\hline Eremanthus & - & 0,4 & - & - & - & - & - & - & - & - \\
\hline Mikeania micrantha & 11,3 & 1,6 & 1 & 0,6 & - & - & 0,2 & - & - & 0,2 \\
\hline Trichogonia & - & - & - & - & - & - & - & 0,4 & - & - \\
\hline Vernonanthura brasiliana & - & - & - & - & - & - & - & 0,2 & 0,4 & 0,6 \\
\hline \multicolumn{11}{|l|}{ Begoniaceae } \\
\hline Begonia & 0,2 & - & - & - & - & - & - & - & - & - \\
\hline \multicolumn{11}{|l|}{ Bignoniaceae } \\
\hline Handroanthus & - & - & - & - & - & - & - & 1,3 & - & - \\
\hline \multicolumn{11}{|l|}{ Burseraceae } \\
\hline Protium heptaphyllum & - & 0,4 & - & - & 0,4 & - & - & - & - & - \\
\hline \multicolumn{11}{|l|}{ Cactaceae } \\
\hline Cactaceae & - & - & 0,2 & 1,6 & - & 0,4 & - & - & - & - \\
\hline \multicolumn{11}{|l|}{ Cleomaceae } \\
\hline Tarenaya & - & - & - & - & - & - & - & 4,7 & - & - \\
\hline \multicolumn{11}{|l|}{ Commelinaceae } \\
\hline Commelina erecta & 0,3 & 0,2 & - & 0,2 & - & - & - & - & - & - \\
\hline \multicolumn{11}{|l|}{ Dilleniaceae } \\
\hline Doliocarpus dentatus & - & - & - & - & - & - & 1,2 & - & - & - \\
\hline \multicolumn{11}{|l|}{ Euphorbiaceae } \\
\hline Ricinus communis & - & 0,6 & - & - & - & - & 1,2 & 0,6 & 2,6 & 0,6 \\
\hline Fabaceae & & & & & & & & & & \\
\hline Aeschynomene paniculata & - & - & - & - & - & - & - & - & - & 11,3 \\
\hline Anadenanthera & - & - & - & 0,2 & - & - & - & - & - & - \\
\hline Dioclea & - & 0,2 & - & - & - & - & - & - & - & - \\
\hline Fabaceae & 0,2 & - & - & 0,2 & - & - & - & - & - & - \\
\hline Machaerium & - & 2 & 0,2 & 1,8 & - & - & - & 0,2 & - & - \\
\hline Mimosa acutistipula & 1 & 1 & 0,7 & 24 & - & - & 30 & - & - & 0,2 \\
\hline Mimosa arenosa & - & - & - & - & - & 8,4 & - & - & - & - \\
\hline Mimosa caesalpiniifolia & - & - & - & - & 0,8 & - & - & 17,5 & - & - \\
\hline Mimosa pudica/sensitiva & 12 & 17 & 15 & 25 & 1,8 & 45,4 & 31 & 5,1 & 77,4 & 67,2 \\
\hline Mimosa quadrivalvis & - & - & - & - & - & - & 0,2 & - & - & - \\
\hline Mimosa tenuiflora & - & - & - & - & - & - & - & - & 0,2 & - \\
\hline Mimosa ulbrichiana & 0,2 & - & 0,2 & 1 & - & - & - & - & - & - \\
\hline Senna & - & 1,6 & 0,4 & - & - & - & - & - & - & 0,4 \\
\hline Lamiaceae & & & & & & & & & & \\
\hline Hyptis 1 & 46,8 & 1,2 & 0,2 & - & 0,4 & 0,2 & - & 0,2 & 1,7 & 1,5 \\
\hline Hyptis 2 & 6,6 & 0,4 & 0,2 & - & - & - & - & - & - & \\
\hline Rhapbiodon echinus & 7,1 & 0,2 & 0,2 & - & - & - & - & - & - & - \\
\hline Lythraceae & & & & & & & & & & \\
\hline Cuphea & - & - & 0,2 & - & - & - & - & - & - & - \\
\hline Malpighiaceae & & & & & & & & & & \\
\hline Heteropterys & - & - & - & - & - & - & - & - & - & 0,2 \\
\hline Malvaceae & & & & & & & & & & \\
\hline Malvaceae & - & - & 0,2 & - & - & - & - & - & - & - \\
\hline Waltheria americana & - & - & - & - & - & - & - & - & - & 0,2 \\
\hline Myrtaceae & & & & & & & & & & \\
\hline Eucalyptus 1 & - & 10 & 63 & 25 & 2,8 & 2,2 & 0,4 & 4,2 & 0,6 & - \\
\hline Eucalyptus 2 & - & - & - & - & - & 0,4 & - & - & - & - \\
\hline Eugenia 1 & - & 6,5 & - & 0,2 & - & - & - & - & - & - \\
\hline Eugenia 2 & - & - & 0,2 & - & - & 0,8 & - & - & - & - \\
\hline Eugenia 3 & - & - & - & - & - & 0,2 & - & - & - & - \\
\hline
\end{tabular}


Tabela 1. Continuação.

\begin{tabular}{|c|c|c|c|c|c|c|c|c|c|c|}
\hline Tipos polínicos & AMO & AMN & AMD & AMJ & $\mathrm{AMF}$ & AMM & AMA & AMMa & $\mathrm{AMAg}$ & AMS \\
\hline Myrcia 1 & 1 & 8,5 & 0,9 & 0,4 & 41,4 & 1 & 0,6 & 2,5 & 13,1 & 2,3 \\
\hline Myrcia 2 & 1,7 & 13 & - & 0,4 & - & 0,6 & - & - & - & - \\
\hline Myrcia 3 & - & 14 & - & 1,6 & - & - & - & - & - & - \\
\hline Myrcia 5 & - & - & - & - & - & 0,2 & - & - & - & - \\
\hline Myrcia 6 & - & - & - & - & - & 0,6 & - & - & - & - \\
\hline Myrcia 7 & - & - & - & - & - & 1,6 & - & - & - & - \\
\hline Myrtaceae & - & - & - & - & - & - & - & 0,4 & - & - \\
\hline Psidium & 1,7 & 13 & - & 0,2 & - & - & 2,2 & - & - & - \\
\hline Syzygium jambolanum & - & - & - & - & - & 0,2 & - & - & - & - \\
\hline \multicolumn{11}{|l|}{ Piperaceae } \\
\hline Piper divaricatum & - & - & - & - & 11,6 & - & 0,6 & - & - & 2,8 \\
\hline \multicolumn{11}{|l|}{ Poaceae } \\
\hline Poaceae & - & 0,4 & 0,7 & 0,4 & - & - & 0,2 & 0,9 & - & - \\
\hline Polygala paniculata & - & - & - & - & - & 0,2 & - & - & - & - \\
\hline \multicolumn{11}{|l|}{ Portulacaceae } \\
\hline Portulaca halimoides & 0,2 & - & - & - & - & - & - & 1,1 & - & - \\
\hline \multicolumn{11}{|l|}{ Rubiaceae } \\
\hline Borreria & - & - & - & - & - & - & - & - & 0,6 & 0,9 \\
\hline Borreria verticillata & 7,5 & 0,6 & 0,2 & 0,4 & 0,4 & - & 0,2 & - & - & 0,8 \\
\hline Mitracarpus & - & - & - & - & - & 0,4 & - & - & - & - \\
\hline Richardia grandiflora & - & - & - & - & - & 0 & - & - & 0,2 & 0,2 \\
\hline Psychotria & - & - & - & - & - & 9,8 & - & - & - & - \\
\hline \multicolumn{11}{|l|}{ Sapindaceae } \\
\hline Cupania & 0,2 & - & - & - & - & - & - & - & 1,7 & 3,6 \\
\hline Serjania & - & 0,2 & - & - & - & - & - & 0,2 & - & 0,2 \\
\hline \multicolumn{11}{|l|}{ Sapotaceae } \\
\hline Chrysophyllum & - & - & - & - & - & 0,2 & - & - & - & - \\
\hline Pouteria & - & - & 1 & 0,8 & - & - & - & - & - & - \\
\hline \multicolumn{11}{|l|}{ Turneraceae } \\
\hline Cecropia 1 & 0,2 & 2,6 & 0,4 & 2 & - & 5,8 & 4,4 & 7,2 & 1,5 & 2,3 \\
\hline Cecropia 2 & - & - & - & - & - & 0,4 & - & - & - & - \\
\hline Indeterminados & 0,2 & - & 0,8 & - & 0,6 & 3,2 & - & - & - & - \\
\hline
\end{tabular}

Tabela 1. Fim.

Tabela 2. Concentração (\%) de tipos polínicos encontrados nos méis de abelha uruçu (Melipona scutellaris).

\begin{tabular}{|c|c|c|c|c|c|c|c|c|c|c|}
\hline Tipos polínicos & UMO & UMN & UMD & UMJ & UMF & UMM & UMA & UMMa & UMAg & UMS \\
\hline \multicolumn{11}{|l|}{ Amaranthaceae } \\
\hline Amaranthus viridis & - & 0,2 & - & - & - & - & - & - & - & - \\
\hline Anacardiaceae & - & - & - & - & - & - & - & - & - & - \\
\hline Anacardium ocidentale & - & - & 0,4 & - & - & 7,1 & - & - & - & - \\
\hline Schinus terebinthifolius & - & 7,6 & - & - & - & - & 13,2 & - & - & - \\
\hline Spondias tuberosa & - & - & - & - & - & - & 2,4 & - & - & - \\
\hline Tapirira guianensis & - & - & - & - & - & 73,4 & 43,6 & 2,4 & 0,8 & - \\
\hline Asteraceae & - & - & - & - & - & - & - & - & - & - \\
\hline Elephantopus & - & - & - & - & - & - & - & - & 0,4 & - \\
\hline Eupatorium & - & - & - & - & - & - & - & - & 0,8 & - \\
\hline Mikania micrantha & - & 1,4 & 0,2 & - & - & - & - & - & - & 0,2 \\
\hline Vernonanthura brasiliana & - & - & - & - & - & - & - & 0,2 & - & - \\
\hline Begoniaceae & - & - & - & - & - & - & - & - & - & - \\
\hline Begonia & - & - & - & - & 0,6 & - & - & - & - & - \\
\hline Bignoniaceae & - & - & - & - & - & - & - & - & - & - \\
\hline Handroanthus & - & - & 0,4 & - & - & - & - & - & - & - \\
\hline Tabebuia & - & - & - & - & 1,4 & - & - & - & - & - \\
\hline Boraginaceae & - & - & - & - & - & - & - & - & - & - \\
\hline Cordia nodosa & - & - & - & - & - & - & - & 0,2 & - & - \\
\hline Brassicaceae & - & - & - & - & - & - & - & - & - & - \\
\hline Brassica & - & - & - & - & - & - & - & - & 0,4 & 0,2 \\
\hline Bromeliaceae & - & - & - & - & - & - & - & - & - & - \\
\hline Bromeliaceae & - & - & - & - & - & - & - & - & - & 13,2 \\
\hline Burseraceae & - & - & - & - & - & - & - & - & - & - \\
\hline Protium heptaphyllum & - & - & 2,4 & - & 4 & - & 0,4 & - & 0,4 & - \\
\hline
\end{tabular}


Tabela 2 Continuação.

\begin{tabular}{|c|c|c|c|c|c|c|c|c|c|c|}
\hline Tipos polínicos & UMO & UMN & UMD & UMJ & UMF & UMM & UMA & UMMa & UMAg & UMS \\
\hline Cactaceae & - & - & - & - & - & - & - & - & - & - \\
\hline Cactaceae & - & - & - & 0,4 & - & - & - & - & - & - \\
\hline Cannabaceae & - & - & - & - & - & - & - & - & - & - \\
\hline Celtis & - & 0,4 & - & - & - & - & - & - & - & - \\
\hline Trema & - & - & - & - & - & - & 0,6 & - & - & - \\
\hline Combretaceae & - & - & - & - & - & - & - & - & - & - \\
\hline Combretum & - & - & - & 9,2 & - & - & 9,8 & 3,8 & - & - \\
\hline Dilleniaceae & - & - & - & - & - & - & - & - & - & - \\
\hline Tetracera & - & - & - & - & - & - & 0,2 & - & - & - \\
\hline Erythroxylaceae & - & - & - & - & - & - & - & - & - & - \\
\hline Erythroxylum & - & - & - & - & - & - & 0,2 & - & - & - \\
\hline Fabaceae & - & - & - & - & - & - & - & - & - & - \\
\hline Acacia & - & - & - & - & 0,2 & - & - & - & - & - \\
\hline Aeschynomene paniculata & 1,2 & - & - & - & - & - & - & - & - & 29,4 \\
\hline Anadenanthera & 0,4 & 0,8 & 0,4 & 0,2 & 0,4 & - & - & - & 0,4 & - \\
\hline Caesalpinia & - & 0,6 & 1,2 & - & - & - & - & - & - & - \\
\hline Chamaecrista & - & 3,6 & - & - & - & - & - & 0,2 & - & - \\
\hline Fabaceae 1 & 0,6 & - & - & - & 0,2 & - & 0,2 & - & - & - \\
\hline Fabaceae 2 & - & 0,2 & - & - & - & - & - & - & - & - \\
\hline Fabaceae 3 & - & 0,2 & - & - & - & - & - & - & - & - \\
\hline Fabaceae 4 & - & 0,2 & - & - & - & - & - & - & - & - \\
\hline Fabaceae 5 & - & - & 17,2 & - & - & - & - & - & - & - \\
\hline Fabaceae 6 & - & - & 0,4 & - & - & - & - & - & - & - \\
\hline Machaerium & - & - & 1,4 & - & - & - & 1 & - & - & - \\
\hline Mimosa & - & - & - & - & - & - & - & 0,2 & - & - \\
\hline Mimosa acutistipula & 35 & 2,4 & 1,2 & 2,6 & - & 1 & 8,8 & 31,2 & - & - \\
\hline Mimosa arenosa & - & - & - & - & 7,4 & 0,2 & - & - & 3,9 & 7,8 \\
\hline Mimosa misera & 2,4 & - & - & - & - & - & - & - & - & - \\
\hline Mimosa pudica/sensitiva & 26,4 & 2,4 & 0,4 & 0,6 & 8,2 & 0,8 & - & 1,4 & 4,2 & 3,6 \\
\hline Mimosa subenervis & - & - & - & - & - & 0,2 & - & - & - & - \\
\hline Mimosa tenuiflora & - & 0,2 & - & - & - & - & - & - & - & - \\
\hline Piptadenia & - & 0,6 & - & - & - & - & - & - & - & - \\
\hline Poeppigia & - & - & - & - & - & - & - & 0,4 & - & - \\
\hline Senna & - & 3 & 2,4 & - & - & - & 0,8 & 1 & 0,8 & - \\
\hline Zornia & - & - & 2,8 & - & - & - & 2,4 & - & - & - \\
\hline Malpighiaceae & - & - & - & - & - & - & - & - & - & - \\
\hline Byrsonima & - & - & - & - & - & - & 1,6 & - & - & - \\
\hline Melastomataceae & - & - & - & - & - & - & - & - & - & - \\
\hline Clidemia & - & - & - & 7,8 & - & - & - & - & - & - \\
\hline Miconia 1 & 6,2 & 0,8 & 2 & - & 3,8 & 6,9 & - & - & 2,3 & 2,8 \\
\hline Miconia 2 & - & - & - & - & - & - & - & - & 0,4 & - \\
\hline Myrtaceae & - & - & - & - & - & - & - & - & - & - \\
\hline Calycolpus legrandii & - & - & - & - & - & - & - & - & 0,4 & - \\
\hline Campomanesia & - & - & - & - & 0,4 & - & - & - & - & - \\
\hline Eucalyptus & - & 1,6 & - & - & 5 & 0,3 & 1,6 & 1,4 & 4,6 & 0,8 \\
\hline Eugenia 1 & 3,4 & 23,4 & 0,6 & 0,8 & - & - & - & - & - & - \\
\hline Eugenia 2 & - & 3,4 & - & - & 8,2 & - & - & - & 27 & 17,8 \\
\hline Eugenia 3 & - & - & - & - & 3,4 & - & - & - & - & - \\
\hline Eugenia 4 & - & - & - & - & 0,2 & 0,7 & - & - & - & - \\
\hline Eugenia 5 & - & - & - & - & - & - & - & - & - & 0,2 \\
\hline Myria 1 & 2,6 & - & 17,8 & 29 & 6,4 & 1 & 10,8 & 51,8 & 2,3 & 0,6 \\
\hline Myrcia 2 & - & - & 3 & - & 4 & - & 1,6 & - & 3,1 & - \\
\hline Myrcia 3 & 0,8 & - & - & 5 & 5,4 & - & - & - & 0,8 & - \\
\hline Myrcia 4 & - & - & - & - & 12,2 & 0,3 & - & - & 2,7 & 0,8 \\
\hline Myrcia 5 & - & - & - & - & 0,6 & - & - & - & - & - \\
\hline Myrcia 6 & - & - & - & - & 4,6 & - & - & - & 2,3 & 0,4 \\
\hline Myrcia 7 & - & - & - & - & 1,2 & - & - & - & - & 0,2 \\
\hline Myrcia 8 & - & - & - & - & 0,8 & - & - & - & 4,2 & 5,6 \\
\hline Myria 9 & - & - & - & - & 0,6 & 1 & - & - & - & - \\
\hline Myrcia 10 & - & - & - & - & - & 4,3 & - & - & 2,7 & - \\
\hline Myria 11 & - & - & - & - & - & 0,7 & - & - & 23,2 & 1,4 \\
\hline Myrcia 12 & - & - & - & - & - & 0,3 & - & - & - & - \\
\hline Myrtaceae & - & - & - & - & 2,4 & 0,2 & - & 5,2 & - & - \\
\hline Psidium 1 & 15,2 & 17,6 & 6 & 2,4 & 0,2 & - & 0,4 & - & 1,5 & 2 \\
\hline Psidium 2 & - & - & - & - & 1,8 & - & - & - & - & - \\
\hline Syzygium jambolanum & - & - & - & - & 2,6 & 1 & - & - & - & - \\
\hline Plantaginaceae & - & - & - & - & - & - & - & - & - & - \\
\hline Angelonia & - & - & - & - & - & - & - & - & 0,4 & 1,6 \\
\hline Poaceae & - & - & - & - & - & - & - & - & - & - \\
\hline Poaceae & - & 1,2 & - & - & - & - & - & - & - & - \\
\hline
\end{tabular}


Tabela 2 Continuação.

\begin{tabular}{|c|c|c|c|c|c|c|c|c|c|c|}
\hline Tipos polínicos & UMO & UMN & UMD & UMJ & UMF & UMM & UMA & UMMa & UMAg & UMS \\
\hline Rubiaceae & - & - & - & - & - & - & - & - & - & - \\
\hline Mitracarpus & - & - & - & - & - & - & - & - & 0,4 & - \\
\hline Tocoyena & - & - & 0,2 & - & - & - & - & - & - & - \\
\hline Sapindaceae & - & - & - & - & - & - & - & - & - & - \\
\hline Cupania & - & - & 0,2 & - & - & - & - & - & 6,2 & 10,4 \\
\hline Paullinea racemosa & - & 0,4 & 1,4 & - & - & - & - & - & - & - \\
\hline Serjania & - & 1 & 0,4 & - & - & - & - & - & - & - \\
\hline Sapotaceae & - & - & - & - & - & - & - & - & - & - \\
\hline Pouteria & 4,8 & 26,8 & 34,8 & 42 & - & - & - & - & - & - \\
\hline Urticaceae & - & - & - & - & - & - & - & - & - & - \\
\hline Cecropia & 1 & - & 0,6 & - & 0,6 & - & - & - & 0,8 & - \\
\hline Indeterminados & - & - & 2,2 & - & 13,2 & 0,6 & 0,4 & 0,6 & 2,6 & 1 \\
\hline
\end{tabular}

Tabela 2. Fim.

Tabela 3. Concentração (\%) de tipos polínicos encontrados nos méis de abelha jataí (Tetragonisca angustula).

\begin{tabular}{|c|c|c|c|c|c|c|c|c|c|c|}
\hline Tipos polínicos & $\mathrm{JMO}$ & $\mathrm{JMN}$ & JMD & JMJ & JMF & JMM & JMA & JMMa & JMAg & JMS \\
\hline Amaranthaceae & - & - & - & - & - & - & - & - & - & - \\
\hline Alternanthera brasiliana & 4,4 & 1,8 & - & - & - & - & - & - & 2,3 & 38,2 \\
\hline Amaranthus viridis & 0,4 & - & - & - & - & - & - & - & - & - \\
\hline Anacardiaceae & - & - & - & - & - & - & - & - & - & - \\
\hline Anacardium ocidentale & - & 1,4 & - & 13,8 & 26,4 & 21,6 & - & - & - & - \\
\hline Schinus terebinthifolius & 6,7 & - & - & - & - & - & 77,2 & 79,4 & - & 9 \\
\hline Spondias tuberosa & 0 & 1,4 & 2,9 & 6,8 & 3,8 & - & - & - & - & 0,2 \\
\hline Tapirira guianensis & 2,2 & 63 & 88,3 & 32,6 & 34,4 & 72,2 & 17,4 & 15,4 & - & 0,3 \\
\hline Arecaceae & - & - & - & - & - & - & - & - & - & - \\
\hline Cocos nucifera & 0,9 & - & - & - & - & - & - & - & - & - \\
\hline Asteraceae & - & - & - & - & - & - & - & - & - & - \\
\hline Bidens pilosa & 2,2 & - & - & - & - & - & - & - & - & - \\
\hline Chaptalia nutans & 0,9 & - & - & - & - & - & - & - & - & - \\
\hline Conocliniopsis prassifolia & - & - & 1,2 & - & - & - & - & - & - & - \\
\hline Mikeania micrantha & - & 0,4 & - & 0,2 & - & - & - & - & - & 0,9 \\
\hline Vernonanthura brasiliana & 0,9 & 0,2 & - & - & - & - & - & - & 0,8 & - \\
\hline Bromeliaceae & - & - & - & - & - & - & - & - & - & - \\
\hline Bromeliaceae & 0,4 & - & - & - & - & - & - & - & - & - \\
\hline Burseraceae & - & - & - & - & - & - & - & - & - & - \\
\hline Protium heptaphyllum & 1,8 & - & - & - & - & - & - & - & - & 0,2 \\
\hline Cannabaceae & - & - & - & - & - & - & - & - & - & - \\
\hline Celtis & - & - & - & - & - & - & - & - & - & 0,5 \\
\hline Trema & - & - & 0,2 & - & - & - & - & - & - & - \\
\hline Combretaceae & - & - & - & - & - & - & - & - & - & - \\
\hline Combretum & - & - & - & - & - & - & - & - & - & 2,2 \\
\hline Erythroxylaceae & - & - & - & - & - & - & - & - & - & - \\
\hline Erythroxylum & - & - & - & - & - & - & 0,4 & - & - & 4,5 \\
\hline Euphorbiaceae & - & - & - & - & - & - & - & - & - & - \\
\hline Actinostemon & - & - & - & - & - & - & - & - & 0,8 & - \\
\hline Euphorbia & 15,1 & 2,8 & - & - & - & - & - & - & 2,3 & - \\
\hline Ricinus communis & - & 0,2 & - & - & - & - & - & - & 0 & - \\
\hline Fabaceae & - & - & - & - & - & - & - & - & - & - \\
\hline Aeschynomene & - & - & - & - & - & - & - & - & 71,9 & - \\
\hline Aeschynomene paniculata & 1,3 & 3,6 & - & - & - & - & - & - & - & - \\
\hline Caesalpinia & - & - & - & - & 0,2 & 3,6 & - & - & - & - \\
\hline Dioclea & - & 1,4 & - & - & - & - & - & - & - & - \\
\hline Fabaceae & 0,4 & 3,2 & - & - & - & - & - & - & - & - \\
\hline Inga & - & 0,4 & - & - & - & - & - & - & - & - \\
\hline Machaerium & - & 7,4 & - & - & - & - & - & - & - & 1,9 \\
\hline Mimosa & 0,9 & - & 0,4 & - & - & - & - & - & - & - \\
\hline Mimosa arenosa & - & - & - & - & - & 0,4 & - & - & - & 0,5 \\
\hline Mimosa pudica/sensitiva & 28 & - & - & - & - & - & 0,8 & - & 8,6 & 0,9 \\
\hline Mimosa quadrivalvis & - & - & - & - & 0,2 & - & - & 0,2 & - & - \\
\hline Parapiptadenia & - & - & - & 0,4 & - & - & - & - & - & - \\
\hline Senna & 0,4 & - & 1 & - & - & - & - & - & - & 4,1 \\
\hline Lamiaceae & - & - & - & - & - & - & - & - & - & - \\
\hline Hyptis & 0,4 & - & - & - & - & - & - & - & - & - \\
\hline Loranthaceae & - & - & - & - & - & - & - & - & - & - \\
\hline Psittacanthus & - & - & - & - & - & - & - & 0,4 & - & - \\
\hline Malpighiaceae & - & - & - & - & - & - & - & - & - & - \\
\hline Banisteriopsis & 0,4 & - & - & - & - & - & - & - & - & - \\
\hline Byrsonima 1 & 0,4 & - & 2,5 & 38,4 & 35 & 2 & - & 1 & - & - \\
\hline Byrsonima 2 & - & - & - & - & - & - & - & - & 8,6 & - \\
\hline Malvaceae & - & - & - & - & - & - & - & - & - & - \\
\hline Herissantia tiubae & - & 0,4 & - & - & - & - & - & - & - & - \\
\hline
\end{tabular}


Tabela 3. Concentração (\%) de tipos polínicos encontrados nos méis de abelha jataí (Tetragonisca angustula).

\begin{tabular}{|c|c|c|c|c|c|c|c|c|c|c|}
\hline Tipos polínicos & JMO & $\mathrm{JMN}$ & JMD & JMJ & JMF & JMM & JMA & JMMa & JMAg & JMS \\
\hline Melastomataceae & - & - & - & - & - & - & - & - & - & - \\
\hline Miconia & 0,9 & - & - & - & - & - & - & - & - & - \\
\hline Myrtaceae & - & - & - & - & - & - & - & - & - & - \\
\hline Eucalyptus & 0,4 & - & - & - & - & - & - & - & - & - \\
\hline Eugenia & - & 0,2 & - & - & - & - & - & - & - & - \\
\hline Myrcia & 14,7 & 0,4 & 1,6 & - & - & - & - & - & - & - \\
\hline Oxalidaceae & - & - & - & - & - & - & - & - & - & - \\
\hline Oxalis & - & - & - & - & - & - & - & - & 0,8 & - \\
\hline Peraceae & - & - & - & - & - & - & - & - & - & - \\
\hline Pera glabrata & - & - & - & - & - & - & - & - & 1,6 & - \\
\hline Plantaginaceae & - & - & - & - & - & - & - & - & - & - \\
\hline Angelonia & 1,3 & - & - & - & - & - & - & - & - & - \\
\hline Poaceae & - & - & - & - & - & - & - & - & - & - \\
\hline Poaceae & - & - & - & - & - & - & - & 0,2 & - & 0,9 \\
\hline Rubiaceae & - & - & - & - & - & - & - & - & - & - \\
\hline Borreria latifolia & - & 3,6 & 0,8 & - & - & - & - & - & - & - \\
\hline Borreria verticillata & 0,4 & 3 & 0,6 & 0,4 & - & - & 0,4 & - & 1,6 & 0,2 \\
\hline Mitracarpus & - & - & - & - & - & - & - & 1,2 & - & 0,2 \\
\hline Sapindaceae & - & - & - & - & - & - & - & - & - & - \\
\hline Cupania & - & - & - & - & - & - & 0,6 & - & - & 0,5 \\
\hline Sapindaceae & - & 2,2 & - & - & - & - & - & - & - & - \\
\hline Sapotaceae & - & - & - & - & - & - & - & - & - & - \\
\hline Chrysophyllum & - & - & - & - & - & - & - & - & - & 34,9 \\
\hline Pouteria & 1,8 & - & - & - & - & - & - & - & - & - \\
\hline Urticaceae & - & - & - & - & - & - & - & - & - & - \\
\hline Cecropia & 9,3 & 3 & 0,6 & 3,8 & - & 0,2 & 0,2 & - & - & - \\
\hline Indeterminados & 2,5 & - & - & 3,6 & - & - & 3 & 2,2 & 0,8 & - \\
\hline
\end{tabular}

Tabela 4. Tipos polínicos dominantes e acessórios ocorrentes nas amostras de Apis mellifera, Melipona scutellaris e Tetragonisca angustula.

\begin{tabular}{|c|c|c|c|}
\hline Classe Abelha & Apis mellifera & Melipona scutellaris & Tetragonisca angustula \\
\hline $\begin{array}{l}\text { Pólen dominante } \\
(>45 \%)\end{array}$ & $\begin{array}{l}\text { Eucalyptus } 1 \text {, Hyptis } 1 \text {, Mimosa pudica/sensitiva } \\
\text { e Tapirira guianensis }\end{array}$ & Myrcia 1 e Tapirira guianensis & $\begin{array}{l}\text { Aeschynomene, Schinus terebinthifolius e } \\
\text { Tapirira guianensis }\end{array}$ \\
\hline $\begin{array}{l}\text { Pólen acessório } \\
(15-45 \%)\end{array}$ & $\begin{array}{l}\text { Eucalyptus } 1, \text { Mimosa acutistipula, Mimosa } \\
\text { caesalpiniifolia, Mimosa pudica/sensitiva, Myrcia } \\
\text { 1, Schinus terebinthifolius e Tapirira guianensis }\end{array}$ & $\begin{array}{l}\text { Aeschynomene paniculata, Eugenia 1, Eugenia 2, } \\
\text { Fabaceae 5, Mimosa acutistipula, Mimosa pudical } \\
\text { sensitiva, Myrcia 1, Myrcia 11, Pouteria, Psidium } 1 \mathrm{e} \\
\text { Tapirira guianensis }\end{array}$ & $\begin{array}{l}\text { Alternanthera brasiliana, Anacardium } \\
\text { ocidentale, Byrsonima 1, Chrysophyllum, } \\
\text { Mimosa pudica/sensitiva e Tapirira } \\
\text { guianensis }\end{array}$ \\
\hline
\end{tabular}

Tabela 5. Concentrações inibitórias mínimas $(\mathrm{mg} / \mathrm{mL})$ para as amostras de méis de Apis mellifera, Melipona scutellaris e Tetragonisca angustula testadas contra Escherichia coli, Psendomonas aeruginosa, Staphylococcus aureus e Candida albicans.

\begin{tabular}{|c|c|c|c|c|c|}
\hline \multirow{2}{*}{ Abelhas } & \multirow{2}{*}{ Amostras } & \multicolumn{4}{|c|}{$\begin{array}{l}\text { Microrganismos } \\
\end{array}$} \\
\hline & & Escherichia coli & Pseudomonas aeruginosa & Staphylococcus aureus & Candida albicans \\
\hline \multirow{9}{*}{ 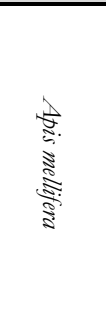 } & $\mathrm{AMO}$ & - & - & 10 & - \\
\hline & $\mathrm{AMN}$ & - & - & 10 & - \\
\hline & $\mathrm{AMJ}$ & - & - & 10 & - \\
\hline & AMF & - & - & 10 & - \\
\hline & AMM & - & - & 10 & - \\
\hline & AMA & - & - & 10 & - \\
\hline & AMMa & - & - & 10 & - \\
\hline & AMAg & - & - & - & - \\
\hline & AMS & - & - & 10 & - \\
\hline \multirow{9}{*}{ 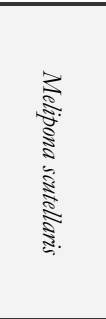 } & UMO & - & - & - & - \\
\hline & UMN & - & - & - & - \\
\hline & UMD & - & - & - & - \\
\hline & UMJ & - & - & - & - \\
\hline & UMF & - & - & - & - \\
\hline & UMM & - & - & - & - \\
\hline & UMMa & - & - & - & - \\
\hline & UMAg & - & - & 10 & - \\
\hline & UMS & - & - & 10 & - \\
\hline \multirow{10}{*}{ 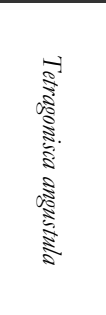 } & JMO & - & - & - & - \\
\hline & $\mathrm{JMN}$ & - & - & - & - \\
\hline & JMD & - & - & - & - \\
\hline & JMJ & - & - & - & - \\
\hline & JMF & - & - & - & - \\
\hline & JMM & - & - & - & - \\
\hline & JMA & - & - & - & - \\
\hline & JMMa & - & - & 10 & - \\
\hline & JMAg & - & - & - & - \\
\hline & JMS & - & - & 10 & - \\
\hline
\end{tabular}


Figura 2. Alguns dos tipos polínicos registrados nos méis estudados. Escala $10 \mu \mathrm{m}$.

Schinus terebinthifolius

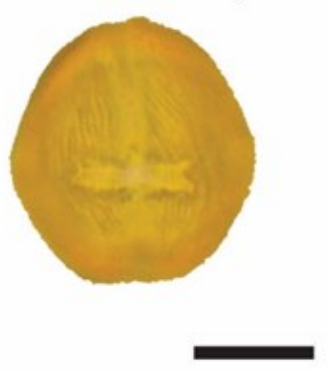

Commelina erecta

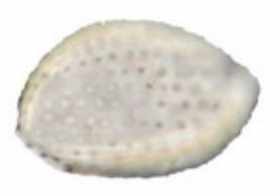

Anadenanthera

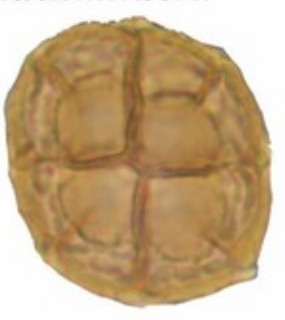

一

Hyptis 1

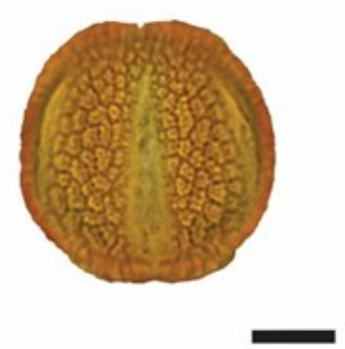

Myria 1

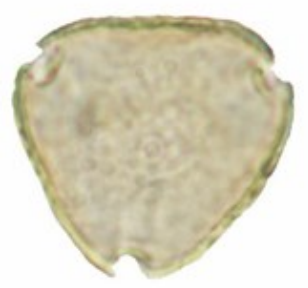

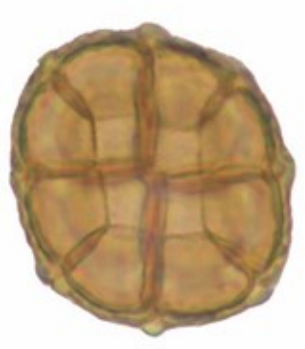
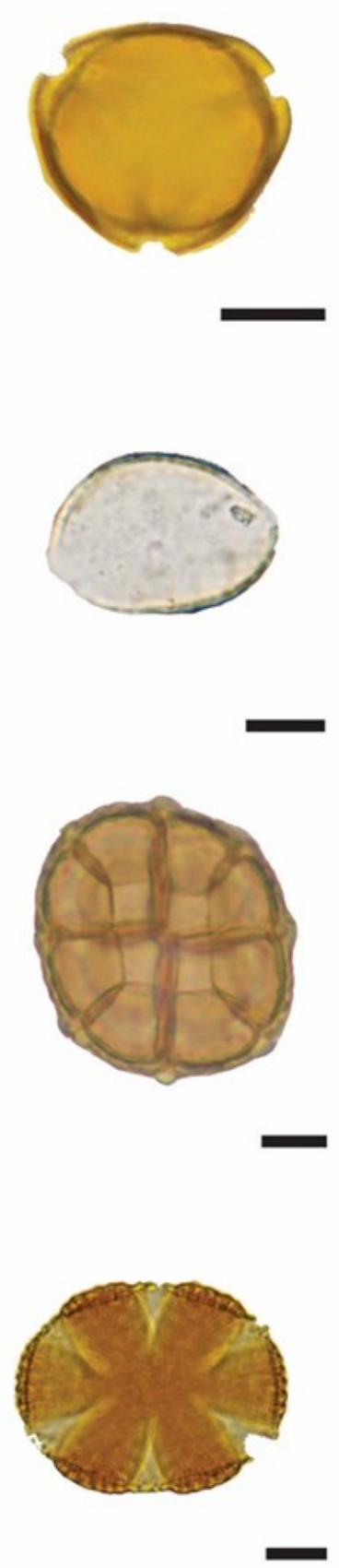

Psidium 1

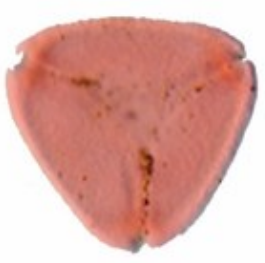

Protium beptaphyllum

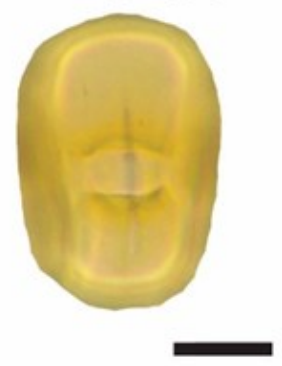

Ricinus communis

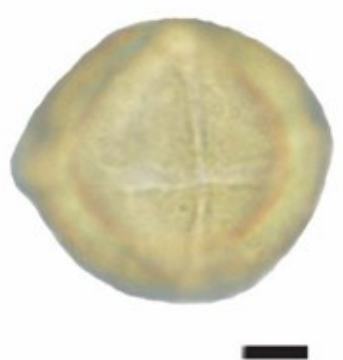

Mimosa acutistipula
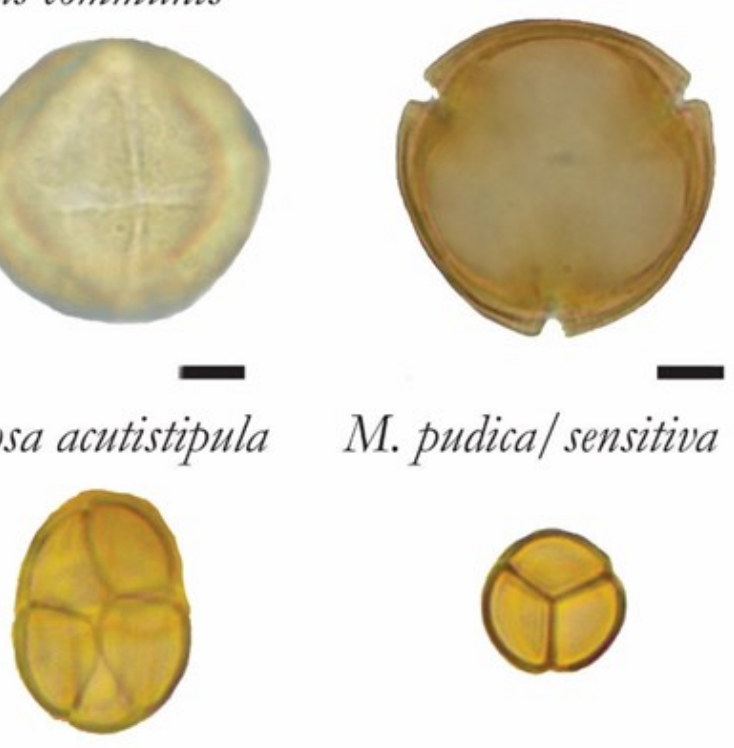

M. pudica/sensitiva

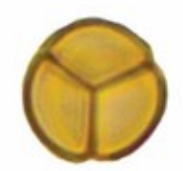

Eucalyptus 1
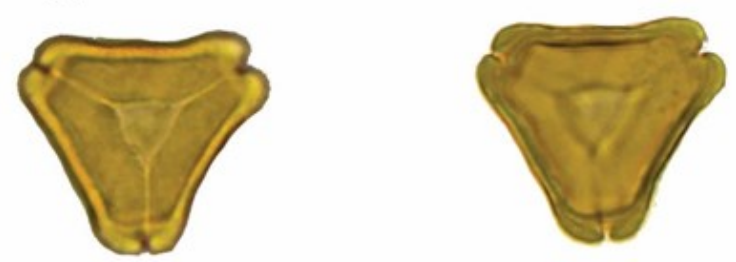

Cecropia 1
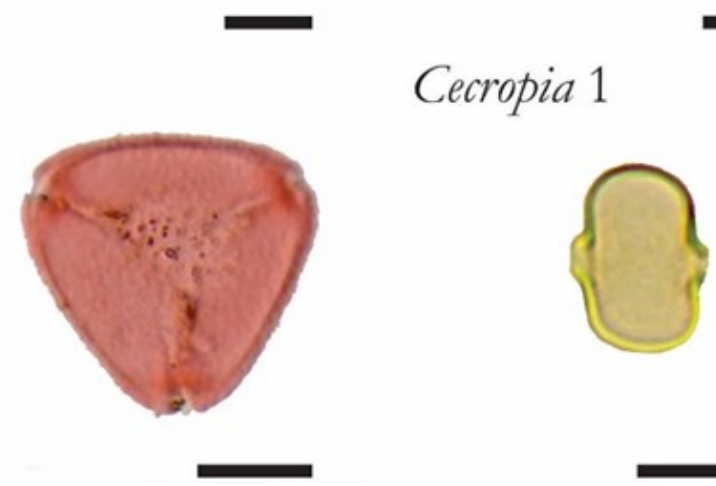
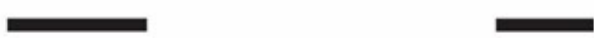
Figura 3), sugerindo que as abelhas da espécie M. scutellaris exploram um maior número de recursos para a produção dos méis. Essa diversidade de tipos polínicos é também reflexo de uma estratégia alimentar generalista, aceita como padrão entre as abelhas eussociais da família Apidae, que possibilita a exploração de uma grande variedade de recursos alimentares, permitindo que a espécie se adeque às variações na oferta de alimentos (Ramalho et al., 2007).

Vinte tipos polínicos foram compartilhados nos méis das três espécies de abelhas (Figura 3): Aeschynomene paniculata, Cecropia 1, Cupania, Eucalyptus 1, Eugenia 1, Fabaceae 1, Machaerium, Mikania micrantha, Mimosa arenosa, Mimosa pudica/sensitiva, Mitracarpus, Myrcia 1, Poaceae, Pouteria, Protium heptaphyllum, Schinus terebinthifolius, Senna, Spondias tuberosa, Tapirira guianensis e Vernonanthura brasiliana. Esses tipos polínicos são indicadores de espécies que merecem atenção especial, pois, atendem às necessidades nutricionais das três espécies de abelhas estudadas.

Figura 3. Número de tipos polínicos encontrados nas amostras de méis de Apis mellifera, Melipona scutellaris e Tetragonisca angustula.

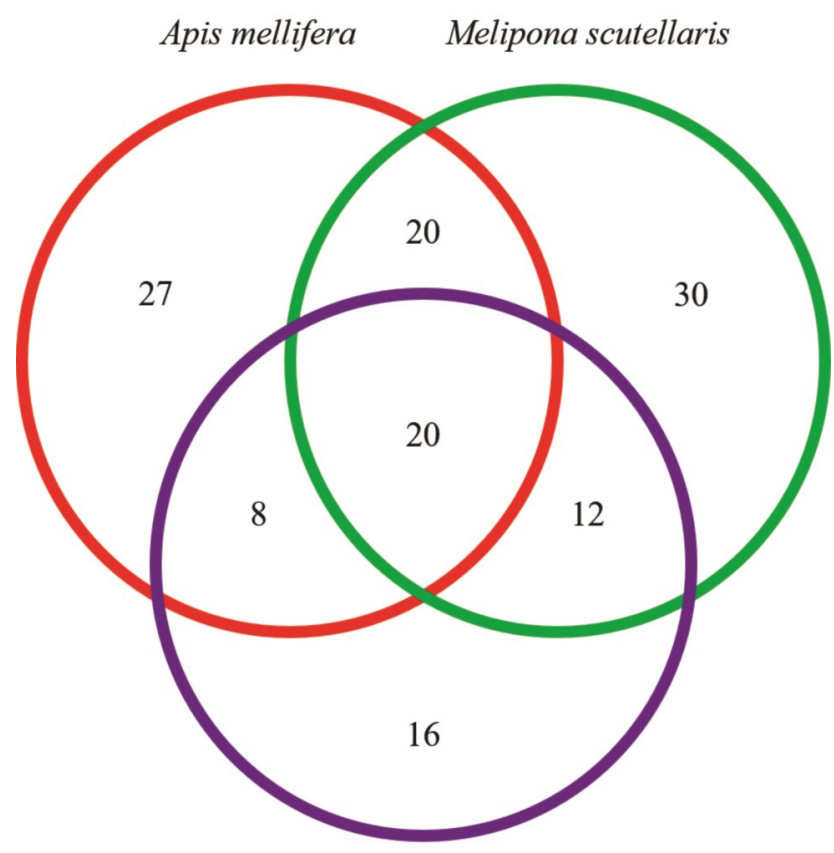

Tetragonisca angustula

Em meio aos tipos polínicos compartilhados, nove deles são indicadores de plantas fornecedoras de pólen e néctar: Aeschynomene paniculata, Eucalyptus 1, Fabaceae 1, Mikania micrantha, Mimosa arenosa, Mitracarpus, Pouteria, Schinus terebinthifolius, Spondias tuberosa, Tapirira guianensis; outros quatro, a plantas fornecedoras de néctar: Cupania, Machaerium, Vernonanthura brasiliana; e o tipo polínico Protium heptaphyllum, apontando espécie produtora de néctar e resina (Lenza; Oliveira, 2005; Matos; Santos, 2019; RCPOL, 2019).

Tratando das classes de frequência dos tipos polínicos encontradas nos méis estudados, as amostras de $A$. mellifera apresentaram quatro tipos polínicos na classe dominante, com frequência $>45 \%$. Entre os méis de M. scutellaris, apenas duas amostras apresentaram tipos polínicos na mesma classe; nos méis de T. angustula, seis amostras apresentaram um tipo polínico dominante. Sete tipos polínicos foram classificados como pólen acessório em ao menos uma amostra de A. mellifera, 11 nas amostras de $M$. scutellaris e seis tipos polínicos nos de T. angustula (Tabela 4).

Todos os demais tipos polínicos encontrados e não menciona-

Figura 4. Diagrama de ordenação de amostras de méis de Apis mellifera $(\times)$, Melipona scutellaris $(\diamond)$ e Tetragonisca angustula $(0)$ com base no espectro polínico, utilizando análise de coordenadas principais.

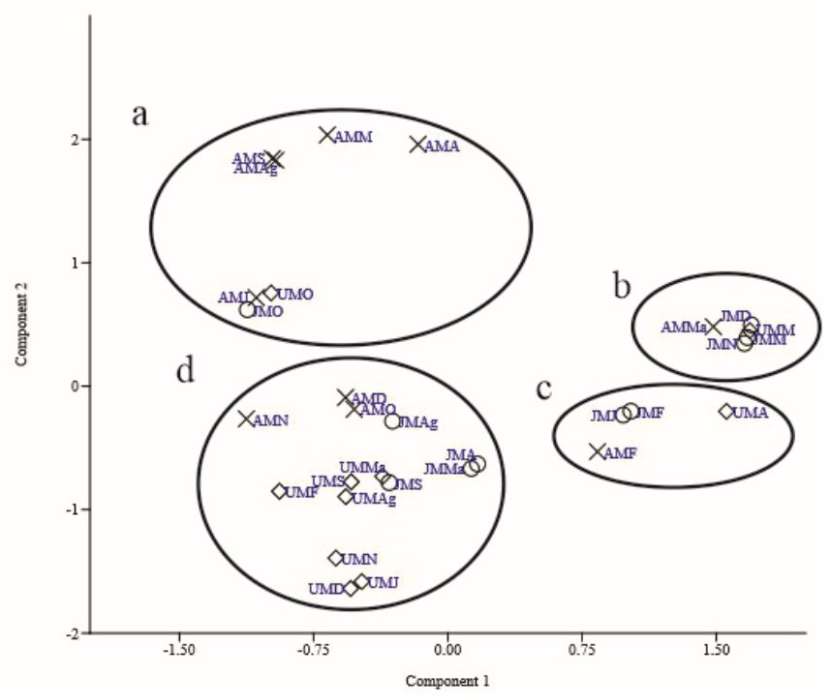

dos como pólen dominante ou acessório, ocuparam a classe de frequência de pólen isolado, apontando a característica de heterogeneidade na composição dos méis na região. Essa heterogeneidade fica ainda mais clara ao observar a distribuição espacial desses méis quanto aos seus tipos polínicos (Figura 4).

$\mathrm{Na}$ PCA aplicada aos dados palinológicos (Figura 4), observase a indistinção da maioria das amostras quanto ao espectro polínico. A distribuição encontrada parece ser influenciada pelo grande número de tipos que ocorreram em baixas frequências nos méis da região e que os caracterizam como méis heterogêneos - produzidos a partir de diversas fontes vegetais. Apesar disso, é possível delinear quatro grupos de amostras: o grupo A, formado por amostras com participação do tipo polínico Mimosa pudica/sensitiva como pólen acessório; o grupo B, formado por amostras que apresentam o tipo polínico Tapirira. guianensis como dominante; o grupo C, formado por amostras com o tipo T. guianensis presente na classe de frequência de pólen acessório; e o grupo $\mathrm{D}$, composto por todos os demais méis que não apresentam nenhum tipo polínico comum a todos os componentes do agrupamento.

Considerando-se os tipos polínicos encontrados nas classes de frequência representadas por pólen dominante e pólen acessório (Tabela 4) e valores próximos a estes, levando-se em consideração também a super e sub-representação polínica e o pólen anemófilo, podemos afirmar que a maioria dos méis é heterofloral. Adotando como critérios para considerar uma amostra como monofloral a presença de um tipo polínico dominante, a ausência de outro tipo polínico com frequência igual ou superior a $10 \%$ na amostra - visto que tipos polínicos com representatividade superior a $10 \%$ sugerem recursos alimentares importantes (Ramalho et al., 1985) -, e o tipo de recurso disponibilizado pelas plantas, podemos considerar apenas quatro amostras como monoflorais. A amostra de março (UMM), da abelha M. scutellaris, e as amostras de novembro (JMN), dezembro (JMD) e agosto (JMAg), de T. angustula - as três primeiras, monoflorais de T. guianensis, e a última, monofloral de Aeschynomene. 
Baseando-se na análise da quantidade de grãos de pólen de cada amostra, nas informações sobre a disponibilidade de recurso das plantas relacionadas aos tipos polínicos e na presença de dois tipos polínicos com frequências superiores a $10 \%$ e que somadas correspondam a uma frequência superior a $75 \%$ na mesma amostra, foram classificados sete amostras como biflorais: duas amostras de A. mellifera (AMAg e AMS), uma de M. scutellaris (UMMa) e quatro amostras de T. angustula (JMM, JMA, JMMa e JMS) (Tabelas 1-3).

Quanto às famílias botânicas, 26 foram representadas nos méis de A. mellifera, 25 nos méis de T. angustula e 24 nos méis de uruçu ( $M$. scutellaris). A família com maior número de tipos polínicos nos méis de A. mellifera e M. scutellaris foi Myrtaceae, enquanto nos méis de jataí (T. angustula), Fabaceae ocupou esta posição (Figura 5).

Quanto à análise do potencial antimicrobiano, os méis em questão não apresentaram atividade antimicrobiana, nas concentrações de $10 \mathrm{mg} / \mathrm{mL}$ a $0,1 \mathrm{mg} / \mathrm{mL}$, contra os microrganismos Eschericbia coli, Pseudomonas aeruginosa e a levedura Candida albicans (Tabela 5). Apenas o microrganismo Staphylococcus aureus foi inibido por amostras (13) dos méis testados (Tabela 5). Segundo Theunissena et al. (2001), S. aureus é um dos organismos incluído na maioria dos estudos comparativos, sendo considerado um dos mais sensíveis à ação antibacteriana do mel. Ressalta-se que $S$. aureus é um dos principais responsáveis por infecções de feridas e septicemia em hospitais, tendo grande importância médica.

Frente à S. aureus, com exceção da amostra de agosto de 2017 (AMAg), todas as amostras de mel de A. mellifera apresentaram atividade antimicrobiana na concentração de $10 \mathrm{mg} / \mathrm{mL}$. Apenas dois méis de M. scutellaris - agosto (UMAg) e setembro (UMS) - e dois de T. angustula - maio (JMM) e setembro (JMS) - apresentaram o mesmo resultado contra esta bactéria. As demais amostras não foram capazes de inibir o microrganismo em nenhuma das concentrações testadas.

Basualdo et al. (2007), testando 15 méis em concentrações muito superiores às testadas em nosso estudo, observaram que apenas nas concentrações de 75 e 100\% (não diluído) alguns méis conseguiram inibir o crescimento de $S$. aureus. Somente a $100 \%$, três das amostras testadas por eles conseguiram inibir o crescimento de P. aeruginosa, ao passo que quatro interferiram no crescimento de E. coli.

Wahdan (1998) também verificou que E. coli, S. aureus e $C$. albicans tiveram crescimento inibido na presença do mel em concen- tração $100 \%$, sendo P. aeruginosa resistente a todas as concentrações testadas. Concentrações menores foram testadas por Sherlock et al. (2010), analisando méis em diluições de 0,02 a 50\% (v/v), quando as concentrações inibitórias mínimas para E. colie P. aeruginosa foram 12,5\% (v/v). Wilkinson e Cavanagh (2005) observaram inibição das mesmas bactérias em todas as amostras de mel com concentrações inibitórias variando de 2,5 a 10\% (p/v). Ainda segundo Wilkinson e Cavanagh (2005), os méis em concentração de 1\% (p/ v) não inibiram nenhum dos microrganismos usados em seu estudo, o que diverge de nosso trabalho, que apresenta amostras com concentração inibitória mínima de $10 \mathrm{mg} / \mathrm{mL}$, o equivalente a uma diluição de $1 \%(\mathrm{p} / \mathrm{v})$.

Avaliando o potencial fungicida de 28 diferentes méis iranianos contra espécies patógenas de Candida, Khosravi et al. (2008) conseguiram a inibição do crescimento de C. albicans em méis em concentrações de 25 a $47 \%$ (v/v). É importante ressaltar que todos os estudos apresentados, que revelam resultados positivos dos méis em combate aos microrganismos enfocados, conseguiram tais feitos utilizando concentrações do produto superiores às testadas por nós.

Apesar de existir uma crença que o mel de abelhas nativas sem ferrão é mais poderoso medicinalmente que o produzido por $A$. mellifera, essa alegação não pôde ser fundamentada por nós ou por Demera e Angert (2004). Miorin et al. (2003) também não notaram a presença de uma diferença significativa entre as MIC dos méis de A. mellifera e T. angustula. Todas essas situações são diferentes dos achados de Ewnetu et al. (2013), os quais constataram que os méis de abelhas-sem-ferrão se destacaram em relação aos méis de $A$. mellifera no combate de $S$. aureus.

Os méis produzidos no mês de setembro, que compartilharam a capacidade de inibir $S$. aureus, apresentaram três tipos polínicos em comum: Cupania, Mikania e Mimosa pudica/sensitiva, em diferentes proporções. Entre esses três tipos, apenas Cupania tem afinidade botânica a plantas nectaríferas. O gênero Cupania apresenta plantas endêmicas do Brasil com reconhecido potencial medicinal (Silva et al., 2014; Pereira et al., 2016; Ricardo et al., 2017; Lucena et al., 2018), fatos que, associados às propriedades antimicrobianas encontradas nos méis avaliados, podem indicar um produto de destaque com uso potencial na medicina, como ocorre com os méis de ulmo e manuka (Sherlock et al., 2010; Bridi; Montenegro, 2017).

Figura 5. Distribuição dos tipos polínicos entre as famílias que se destacaram na composição dos méis de Apis mellifera, Melipona scutellaris e Tetragonisca angustula produzidos em um fragmento de floresta ombrófila densa, no município de Alagoinhas, Bahia.

Apis mellifera

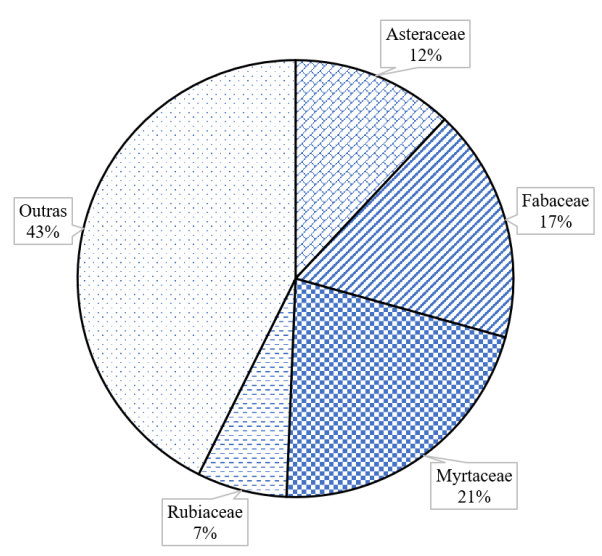

Melipona scutellaris

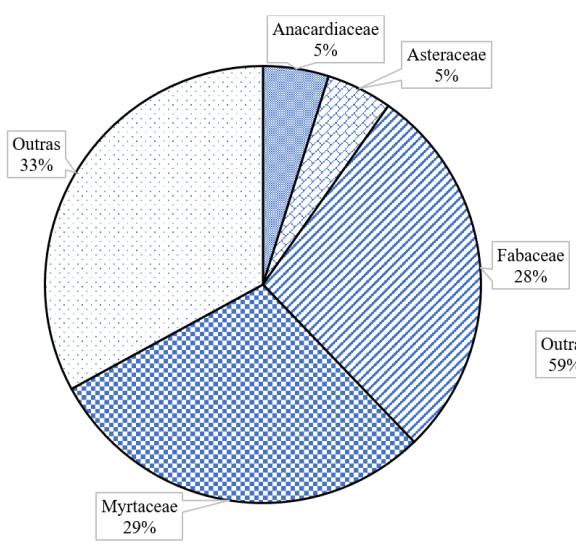

Tetragonisca angustula

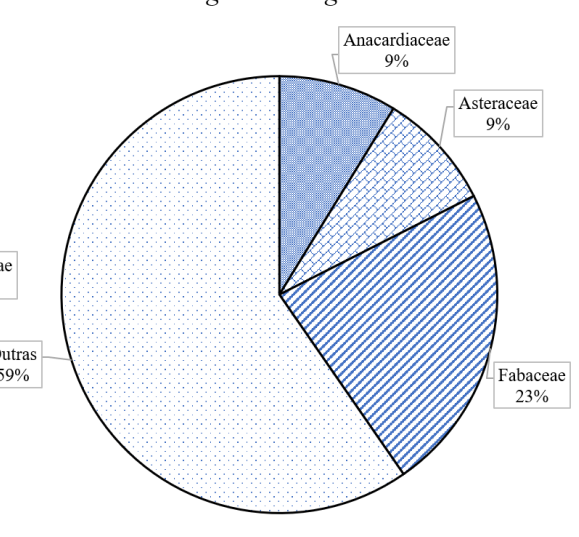




\section{Conclusão}

Quanto à origem botânica, os méis analisados caracterizam-se majoritariamente pela variedade de recursos florais utilizados para a sua constituição, sendo a maior parte deles composta por grãos de pólen na classe de frequência de pólen isolado. A avaliação da atividade antimicrobiana das amostras demonstrou que a maioria dos méis de Apis mellifera pode ser um importante inibidor de crescimento de $S$. aureus. Esse mesmo resultado foi encontrado apenas em duas outras amostras de méis de M. scutellaris e T. angustula.

Os resultados aqui apresentados salientam a importância da investigação dos méis antes do seu uso como tratamento alternativo às infecções causadas por microrganismos ou na elaboração de produtos com finalidade antimicrobiana. A partir do espectro polínico não foi possível separar os méis quanto às espécies que os produzem ou por seu potencial antimicrobiano, sendo observada uma organização intricada na análise de ordenamento.

\section{Agradecimentos}

Ao Programa de Pós-graduação em Botânica da Universidade Estadual de Feira de Santana (UEFS); ao Laboratório de Micromorfologia Vegetal da UEFS, pelo uso das suas instalações; à Coordenação de Aperfeiçoamento de Pessoal de Nível Superior (CAPES), por bolsa de doutorado concedida a MCJ (\#88882.447839/2019-01); e ao Conselho Nacional de Desenvolvimento Científico e Tecnológico (CNPq), por bolsa de doutorado concedida a DCO (processo \#141833/2019-0) e apoio a FARS (\#302594/2016-7 e \#304255/2019-0).

\section{Financiamento}

Coordenação de Aperfeiçoamento de Pessoal de Nível Superior (CAPES) - bolsa de doutorado concedida a MCJ (processo 88882.447839/2019-01). Conselho Nacional de Desenvolvimento Científico e Tecnológico (CNPq) - bolsa de doutorado concedida a DCO (processo \#141833/2019-0) e apoio a FARS (\#302594/2016-7 e \#304255/2019-0)

\section{Contribuições de autoria}

Conceitualização: MCJ, FARS. Curadoria de dados: MCJ. Análise formal: MCJ. Aquisição de financiamento: FARS, MCJ. Investigação: MCJ, DCO, LERF. Metodologia: MCJ, FARS, LERF, HMK, HNB. Administração do projeto: MCJ, FARS. Recursos: MCJ, FARS, LERF, HMK, HNB. Supervisão: FARS. Validação: MCJ, DCO. Visualização: MCJ, DCO, FARS, HMK. Redação -- rascunho original: MCJ, DCO, FARS, HMK. Redação revisão e edição: MCJ, DCO, FARS, HMK.

\section{Conflito de interesses}

Os autores declaram não haver conflitos de interesse a informar.

\section{Disponibilidade dos dados}

Os dados integrais analisados durante o estudo atual podem ser fornecidos mediante solicitação justificada ao autor para correspondência.

\section{Conformidade ética}

Não se aplica.

\section{Referências}

Almeida-Muradian LB, Stramm KM, Horita A, Barth OM, Freitas AS, Estevinho LM. Comparative study of the physicochemical and palynological characteristics of honey from Melipona subnitida and Apis mellifera. International Journal of Food Science and Technology 2013;48:1698-1706. doi: 10.1111/ijfs.12140

APG IV - Angiosperm Phylogeny Group. An update of the angiosperm phylogeny group classification for the orders and families of flowering plants: APG IV. Botanical Journal of the Linnean Society 2016;181:1-20. doi: 10.1111/boj.12385

Bankova V, Popova M, Trusheva B. The phytochemistry of the honeybee. Phytochemistry 2018;(155):1-11. doi: 10.1016/ j.phytochem.2018.07.007

Basualdo C, Sgroy V, Finola MS, Marioli JM. Comparison of the antibacterial activity of honey from diferente provenance against bacteria usually isolated from skin wounds. Veterinary Microbiology 2007;124:375-381. doi: 10.1016/j.vetmic.2007.04.039

Bridi R, Montenegro G. The value of chilean honey: floral origin related to their antioxidant and antibacterial activities. In: Toledo, VAA, editores. Honey Analysis. Croatia: InTech; 2017. p. 63-78.

Carreira LMM, Barth OM. Atlas de pólen da vegetação de canga da Serra de Carajás, Pará, Brasil. Belém: Museu Paraense Emílio Goeldi; 2003.

CLSI. Reference method for broth dilution antifungal susceptibility testing of yeasts; approved standard - third edition. CLSI document M27-A3. Pennsylvania: Clinical and Laboratory Standards Institute; 2008.

CLSI. Methods for dilution antimicrobial susceptibility tests for bacteria that grow aerobically; approved standard - ninth edition. CLSI document M07-A9. Pennsylvania: Clinical and Laboratory Standards Institute; 2012

Demera JH, Angert ER. Comparison of the antimicrobial activity of honey produced by Tetragonisca angustula (Meliponinae) and Apis mellifera from different phytogeographic regions of Costa Rica. Apidologie 2004;35:411-417. doi: 10.1051/apido:2004033

Erdtman G. The acetolysis method. A revised description. Svensk Botanisk Tidskrift 1960;54(4):561-564.

Erler S, Moritz RF. Pharmacophagy and pharmacophory: mechanisms of selfmedication and disease prevention in the honeybee colony (Apis mellifera). Apidologie 2016;47(3):389-411. doi: 10.1007/s13592-015-0400-z

Ewnetu Y, Lemma W, Birhane N. Antibacterial effects of Apis mellifera and stingless bees honeys on susceptible and resistant strains of Eschericbia coli, Staphylococcus aureus and Klebsiella pneumoniae in Gondar, Northwest Ethiopia. BMC Complementary and Alternative Medicine 2013;13(269):1-7. doi: 10.1186/14726882-13-269

Hammer Ø, Harper DAT, Ryan PD. Past: paleontological statistics software package for education and data analysis. Palaeontologia Electronica 2001;4(1):1-9.

Instituto Adolfo Lutz. Métodos físico-químicos para análise de alimentos. São Paulo: Instituto Adolfo Lutz; 2008.

Jesus NG, Almeida GSS, Fonseca MR. Diversidade florística de dois remanescentes de floresta ombrófila densa. In: Nunes JMC, Matos MRB. Litoral Norte da Bahia: Caracterização Ambiental, Biodiversidade e Conservação. Salvador: EDUFBA; 2017. p. 157 -170 .

Jones GD, Bryant Jr. VM. The use of ETOH for the dilution of honey. Grana 2004;43:174-182. doi: $10.1080 / 00173130410019497$ 
Joosten H, De Klerk P. What's a name? Some thoughts on pollen classification, identification, and nomenclature in quaternary palynology. Review of Palaeobotany and Palynology 2002;122:29 -45. doi: 10.1016/S0034-6667(02)00090-8

Khosravi AR, Shokri H, Katiraee F, Ziglari T, Forsi M. Fungicidal potential of different Iranian honeys against some pathogenic Candida species. Journal of Apicultural Research and Bee World 2008;47(4):260-264. doi: 10.1080/00218839.2008.11101471

Lenza E, Oliveira PE. Biologia reprodutiva de Tapirira guianensis Aubl. (Anacardiaceae), uma espécie dióica em mata de galeria do Triângulo Mineiro, Brasil. Brazilian Journal of Botany 2005;28 (1):179-190. doi: 10.1590/S0100-84042005000100015

Lima LCL, Silva FHM, Santos FAR. Palinologia de espécies de Mimosa L. (Leguminosae - Mimosoideae) do Semi-Árido brasileiro. Acta Botanica Brasilica 2008;22(3):794-805. doi: 10.1590/ S0102-33062008000300016.

Lorente FL, Buso Junior AA, Oliveira PE, Pessenda LCR. Atlas palinológico: laboratório ${ }^{14} \mathrm{C}$ - Cena USP. Piracicaba: FEALQ; 2017.

Louveaux J, Maurizio A, Vorwohl G. Methods of melissopalynology. Bee World 1978;59(4):139-157.

Lucena RFP, Lucena CM, Carvalho TKN, Ferreira EC. Organizadores. Plantas e animais medicinais da Paraíba: um olhar da etnobiologia e etnoecologia. Cabedelo: IESP; 2018.

Martínez-Hernandéz E, Cuadriello-Aguilar JI, Téllez-Valdez O, Ramírez-Arriaga E, Sosa-Nájera MS, Melchor-Sánchez JEM, Medina-Camamcho M, Lozano-García MS. Atlas de las plantas y el polen utilizados por las cinco espécies principales de abejas productoras de miel em la Region del Tacana, Chiapas, México. México: Instituto de Geología, Universidad Nacional Autonoma de México; 1993.

Matos VR, Santos FAR. Diagnóstico polínico da geoprópolis de Melipona scutellaris L. (Meliponini, Apidae, Hymenoptera) coletada em uma área de Mata Atlântica no nordeste do Brasil. Paubrasilia 2019;2(1):6-16. doi: 10.33447/paubrasilia.v2i1.19

Melhem TS, Cruz-Barros MAV, Corrêa MAS, Makino-Watanabe H, Silvestre-Capelato MSF, Esteves VLG. Variabilidade polínica em plantas de Campos de Jordão (São Paulo, Brasil). Boletim do Instituto de Botânica 2003;16:1-104.

Miorin PL, Levy Junior NC, Custodio AR, Bretz WA, Marcucci MC. Antibacterial activity of honey and propolis from Apis mellifera and Tetragonisca angustula against Staphylococcus aureus. Journal of Applied Microbiology 2003;95:913-920. doi: 10.1046/j.13652672.2003.02050.x

Molan PC. The antibacterial activity of honey. Bee world 1992;73 (1):5-28. doi: 10.1080/0005772X.1992.11099109

Moncada M, Salas E. Pólen de las plantas melíferas en Cuba. Havana: Centro de Información y Divulgación Agropecuário; 1983.

Montenegro G, Mejías E. Biological applications of honeys produced by Apis mellifera. Biological Research 2013;46:341-345. doi: 10.4067/S0716-97602013000400005

Mulu A, Tessema B, Derbie F. In vitro assessment of the antimicrobial potential of honey on common human pathogens. Ethiopian Journal of Health Development 2004;18(2):107-112. doi: 10.4314/ejhd.v18i2.9945

Pereira LA, Amorim BS, Alves M, Somner GV, Barbosa MRV. Flora da Usina São José, Igarassu, Pernambuco: Sapindaceae. Rodriguésia 2016:67(4):1047-1059. doi: 10.1590/21757860201667414

Ramalho M, Imperatriz-Fonseca VL, Kleinekt-Giovannini A, Cortopassi-Laurino M. Exploitation of floral resources by Plebeia remota Holmberg (Apidae, Meliponinae). Apidologie 1985;16 (3):307-330.

Ramalho M, Silva MDE, Carvalho CAL. Dinâmica de uso de fontes de pólen por Melipona scutellaris Latreille (Hymenoptera: Apidae): uma análise comparativa com Apis mellifera L.

(Hymenoptera: Apidae), no domínio tropical atlântico. Neotropi- cal Entomology 2007;36(1):38-45. doi: 10.1590/S1519566X2007000100005

RCPOL[Internet]. Rede de catálogos polínicos online. [acesso em: 19 jan 2020]. Disponível em: http:/ / chaves.rcpol.org.br/

Ricardo LM, Paula-Souza J, Andrade A, Brandão MGL. plants from the brazilian traditional medicine: species from the books of the polish physician Piotr Czerniewicz (Pedro Luiz Napoleão Chernoviz, 1812-1881). Revista Brasileira de Farmacognosia 2017;27:388-400. doi: 10.1016/j.bjp.2017.01.002.

Roubik DW, Moreno PJE. Pollen and spores of Barro Colorado island. St. Louis: Missouri Botanical Garden; 1991.

Santos FAR. Identificação botânica do pólen apícola. Magistra 2011;23:4-9.

Sherlock O, Dolan A, Athman R, Power A, Gethin G, Cowman S, Humphreys H. Comparison of the antimicrobial activity of Ulmo honey from Chile and Manuka honey against methicillin-resistant Staphylococcus aureus, Escherichia coli and Pseudomonas aeruginosa. BMC Complementary and Alternative Medicine 2010;10(47):1-5. doi: 10.1186/1472-6882-10-47

Silva FHM, Santos FAR, Lima LCL. Flora polínica das caatingas: Estação Biológica de Canudos (Canudos, Bahia, Brasil). Feira de Santana: Micron Bahia; 2016.

Silva S, Anselmo MGV, Dantas WM, Rosa JH, Nunes EM, Soares JP, Alves CAB. Conhecimento e uso de plantas medicinais em uma comunidade rural no município de Cuitegi, Paraíba, Nordeste do Brasil. Gaia Scientia 2014;8(1):248-265.

Stevenson PC, Nicolson SW, Wright GA. Plant secondary metabolites in nectar: impacts on pollinators and ecological functions. Functional Ecology 2017;31(1):65-75. doi: 10.1111/13652435.12761

Theunissena F, Groblera S, Gedaliab I. The antifungal action of three South African honeys on Candida albicans. Apidologie 2001;32:371-379. doi: 10.1051/apido:2001137

Wahdan HAL. Causes of the antimicrobial activity of honey. Infection 1998;26(1):26-35. doi: 10.1007/BF02768748

Wilkinson JM, Cavanagh HMA. Antibacterial activity of 13 honeys against Escherichia coli and Pseudomonas aeruginosa. Journal of $\mathrm{Me}-$ dicinal food 2005;8(1):100-103. doi: 10.1089/jmf.2005.8.100 
Caracterización botánica y evaluación del potencial antimicrobiano de la miel producida por Apis mellifera L, Melipona scutellaris Latreille y Tetragonisca angustula Latreille (Hymenoptera: Apidae) en un fragmento de la densa selva tropical del estado de Bahía, Brasil

Este estudio busca caracterizar, a través de los granos de polen, el origen botánico de muestras de miel producidas por Apis mellifera, Melipona scutellaris y Tetragonisca angustula, identificando recursos vegetales compartidos y analizar la capacidad antimicrobiana de las muestras. Se analizaron 30 muestras y 13 mostraron actividad antimicrobiana contra Staphylococcus aureus. Se identificaron 154 tipos de polen; 133 tenian su afinidad botánica inferida. De estos tipos, 82 se observaron en las mieles de $\underline{M}$. scutellaris, 75 en mieles de $\underline{A}$. mellifera y 56 en mieles de $\underline{T}$. angustula. Se compartieron 20 tipos de polen en las mieles de las tres especies de abejas, donde las familias Myrtaceae y Fabaceae se destacaron por su representatividad. Sólo siete tipos ocuparon la clase de frecuencia de polen dominante. De los datos recopilados, se observa que las mieles estudiadas se caracterizan como multiflorales y sólo algunas de ellas.

Palabras clave: Melisopalinología. Polen. MIC.

Caractérisation botanique et évaluation du potentiel antimicrobien du miel produit par Apis mellifera L., Melipona scutellaris Latreille et Tetragonisca angustula Latreille (Hymenoptera: Apidae) dans un fragment de forêt dense humide de l'État de Bahia, Brésil

L'origine botanique des grains de pollen a été vérifiée dans des échantillons de miel d'Apis mellifera, Melipona scutellaris et Tetragonisca angustula, pour en déduire les espèces partagées et leur capacité antimicrobienne. 30 échantillons ont été analysés, dont 13 inbibaient Staphylococcus aureus. Cent cinquante-quatre types ont été identifiés, dont 133 tubes d'origine botanique présumée. Quatre-vingt deux types observés dans des échantillons de miel de $\underline{M}$. scutellaris, 75 dans des échantillons $d^{\prime} \underline{A}$. mellifera et 56 dans $\underline{T}$. angustula. Vingt types de miel étaient communs dans les échantillons de miel des trois espèces. Les familles botaniques Myrtaceae et Fabaceae se distinguent par leur représentativité. Sept types de pollens avaient une fréquence dominante. Les données des échantillons prélevés indiquent que les miels étudiés sont multifloraux et certains d'entre eux ont une activité antimicrobienne contre $\underline{S}$. aureus. 